\title{
Perceived risk factors in the process of closure and greening of the Lupeni mining operation for the miner workplace
}

\author{
Manuel Cristian Savulescu ${ }^{1 *}$, Andreea Cristina Tataru ${ }^{1}$, Aurora Stanci $^{2}$, Dorin Tataru ${ }^{1}$, and \\ Sorin Mihai Radu ${ }^{1}$ \\ ${ }^{1}$ University of Petrosani, Department of Mechanical and Industrial Engineering and Transports, \\ Universittii street, No.20, Petrosani, Romania \\ ${ }^{2}$ University of Petrosani, Departament of Management, Environmental Engineering and Geology, \\ Universittii street, No.20, Petrosani, Romania
}

\begin{abstract}
Determining the risk factors of a job is a process that requires many studies. Determining risk factors is necessary to prevent accidents at work. The process of closing and greening the Lupeni Mining Exploitation is a very complex one. The closure of the mining operation is done in stages for the underground and the surface based on a closure project. When implementing the closure and greening project, all occupational safety and health regulations must be observed. As part of the process of closing and greening a mining operation, it is necessary to redo the risk factor assessment sheets with additional measures for the closure and greening of the mining operation. In this paper we intend to establish the risk factors for the miner workplace within the Lupeni Mining in the process of closure and greening.
\end{abstract}

\section{Introduction}

The starting point in optimizing the activity of prevention of work accidents and occupational diseases at work is the risk assessment.

Whether it is a job, a workshop or an enterprise, such an analysis allows the ranking of risks according to their size and the efficient allocation of resources for priority measures.

Risk assessment involves identifying all risk factors in the analyzed system and quantifying their size based on the combination of two parameters: severity and frequency of the maximum possible consequence on the human body. Thus, partial risk levels are obtained for each risk factor, respectively global risk levels for the entire analyzed system.

Law no. 319/2006 on safety and health at work contains the following provisions regarding the mandatory risk assessment:

- the employer has the obligation "to assess the risks to the safety and health of workers, including the choice of work equipment, substances or chemical preparations used and the arrangement of workplaces" (art. 7, paragraph 4, letter a);

\footnotetext{
* Corresponding author: savio scm@yahoo.com
} 
- the employer has the obligation "to carry out and be in possession of a risk assessment for occupational safety and health, including for those groups sensitive to specific risks" (art. 12, paragraph 1, letter a).

Also, through the provisions of art. 13, lit. b, Law no. Regulation (EC) No 319/2006 on occupational safety and health states that, in order to ensure occupational safety and health and to prevent accidents at work and occupational diseases, employers are required to 'draw up a prevention and protection plan consisting of technical measures, health, organizational and other nature, based on risk assessment, to be applied according to the unit-specific working conditions".

In accordance with Art. 15, para. 1, of H.G. no. 1425/2006 for the approval of the Methodological Norms for the application of the provisions of the Law on safety and health at work no. 319/2006, the first of the prevention and protection activities carried out within the enterprise and / or unit is represented by "hazard identification and risk assessment for each component of the respective work system executing, workload, means of work / work equipment and work environment/jobs".

To facilitate the fulfillment of employers' legal obligations in the field of occupational injury and disease risk assessment, a relatively large number of methods have been designed and are currently used. [1-6]

In this paper we intend to present the perceived risk factors in the process of closure and greening of the Lupeni mining operation for the miner workplace. The Lupeni Mine is located in Lupeni, Hunedoara County and its activity is the underground coal mining.

For risk assessment, we used the method developed by the I.N.C.D.P.M. Bucharest. The method consists in identifying all the existing risk factors at the analyzed workplace based on pre-established checklists and quantifying the size of the risk based on the combination of severity and frequency of the maximum possible consequence on the human body.

The application of this method ends with two documents that will accompany each job throughout its life:

- job evaluation form and

- prevention measures sheet [1-7]

\section{Job description}

\subsection{The work process}

The work process aims, together with the brigade workers, to perform operations characteristic of the production cycle at work, in order to achieve the norm established in conditions of full work safety in terms of technology, quality and safety of staff.

\subsection{Risk factors identified}

\section{A. Risk factors specific to the means of production / work equipment}

a. Mechanical risk factors:

- $\quad$ injury on the way to and from work;

- collapses at work or on the road to and from work;

- $\quad$ rock falls at work or on the way to and from work;

- $\quad$ injury, wrong manoeuvres during loading / unloading materials in / from wagons or trolleys (support elements, wood, wire mesh, conveyor components, etc.); 
- injuries, wrong manoeuvres during the transport of materials to and from the workplace (support elements, wood, wire mesh, components of the conveyors, etc.);

- free falls of incorrectly positioned parts, tools, material or manual handling.

- moving machine parts - clamping, drive by the scraper conveyor chain, drive group couplings, winch components, drill components, technical equipment components, etc.

- $\quad$ hitting by support elements at work;

- design of particles, abrasive material for drilling operations, cutting of the hammer, breaking of overloads, or by the scraper conveyor chain, the couplings of the drive groups;

- injury on the way to and from work;

- collapses at work or on the way to and from work;

- falling rocks at work or on the road to and from work;

- injury, wrong manoeuvres during loading / unloading of materials in / from wagons or trolleys (support elements, wood, wire mesh, conveyor components, etc.);

- injuries, wrong manoeuvres during the transport of materials to and from the workplace (support elements, wood, wire mesh, components of the conveyors, etc.);

- free falls of incorrectly positioned parts, tools, material or manual handling.

- moving machine parts - clamping, drive by the scraper conveyor chain, drive group couplings, winch components, drill components, technical equipment components, etc.

- $\quad$ hitting by support elements at work;

- design of particles, abrasive material for drilling operations, cutting of the hammer, breaking of overloads, or by the scraper conveyor chain, the couplings of the drive groups;

- $\quad$ injury, wrong manoeuvres, while working on the work front;

- compressed air jet when the air hose explodes or when the connections between the air hose and the supply pipe are destroyed, or between the air hose and the pneumatic equipment (hammer, punching machine);

- direct contact with hazardous surfaces (cutters, spikes, abrasives) represented by the binding wire, the supporting elements, the components of the conveyors, the demolished material, the tools and implements used;

- design of bodies and particles in the event of explosions caused by explosive mixtures in the work environment;

\section{b. Thermal risk factors:}

- accidental contact with very hot surfaces;

- flames or flames in case of methane ignition;

- burns due to explosions and ignitions of methane-air mixture;

- fires, fires due to electrical equipment and installations;

\section{c. Electrical risk factors:}

- $\quad$ electric shock by direct touch, indirect touch, step voltage;

- working with improvisations in electrical equipment and installations;

\section{d. Chemical risk factors:}

- $\quad$ work with explosive substances - flammable;

\section{B. Risk factors specific to the work environment}


a. Physical risk factors:

- permanent air currents;

- noise from the drilling operation, removal from the hammer, scraper conveyors, during the evacuation of the mining mass from the front;

- $\quad$ excessive vibrations of the equipment used (hammers, perforators);

- $\quad$ low and uneven lighting level;

- $\quad$ earthquakes, floods, floods, fires, etc .;

- pneumoconiogenic dusts in the workplace atmosphere (particles, fine dusts, etc.);

b. Chemical risk factors:

- $\quad$ smoke, toxic gases that may occur above the permitted limits $\left(\mathrm{CO}, \mathrm{CO}_{2}\right.$, $\mathrm{SO}_{2} ; \mathrm{CH}_{4} ; \mathrm{NO}_{2}$ );

- $\quad$ explosive powders suspended in the air, explosive gases;

- $\quad$ ignition and explosion due to coal dust and/or $\mathrm{CH}_{4}$;

- burns caused during contact with various chemicals;

- $\quad$ sudden decrease of atmospheric pressure, generating disturbances of the general ventilation, resulting in methane accumulations;

- $\quad$ water floods, stud eruptions, roof hits, gas bags under pressure;

- blowing, emanations from the exploited space, which can generate explosions;

- risk of respiratory failure due to low oxygen concentration in the workplace;

- risk of intoxication due to failure of the equipment (measuring and detecting mine gases);

c. The special character of the environment:

- activity carried out underground 129 hours/month, medium with siliceous powders, with high relative humidity;

\section{Risk factors specific to the workload}

a. Inappropriate content:

- $\quad$ improper working methods (wrong sequence of operations);

- $\quad$ storage of materials to be used or which are defective, on the access roads to the workplace;

- executing assignment with inadequate professional training, or with incomplete training in the field of work safety, or with psychophysiological incompatibilities with the requirements of the workplace;

b. Physical overload:

- dynamic effort when lifting heavy loads (transport and installation of support elements, components of scraper conveyors, materials needed at the work front);

- Psychic overload:

- $\quad$ high work pace, operations that require increased attention;

\section{Risk factors specific to the executor}

a. Wrong actions:

- execution of unforeseen operations in the workload;

- wrong manoeuvres when assembling / disassembling or repairing work equipment (metal support, wood support, scraper conveyor, ventilation column, etc.);

- improper fixing of the drill in the drilling machine, of the pickaxe in the hammer; 
- $\quad$ starting and using the equipment without all the protection and safety devices in operation;

- accident-prone communications, non-compliance with signals, unsynchronization to teamwork;

- non-synchronization of operations, delays or advances in performing technological operations;

- wrong manoeuvres during the execution of various technological operations at the workplace (drilling, loading holes with explosive materials, blasting, lifting beams, directing mining pressure, reassembly, repairing tr, mounting tr, lengthening tr, evacuation of demolished material, bandaging, securing, mounting metal supports, abducting metal supports, digging hearths, mounting wooden yokes, abducting wooden yokes, etc.);

- carrying out works without taking all the safety measures characteristic of the environment and of the respective work, non-compliance with the provisions of the work permit, of the reinforcement monograph, of the work instructions, of the shooting disposition, of any other established regulations;

- performing works to remedy defects, deficiencies, without taking all safety measures provided in work permits, specific work instructions;

- $\quad$ working with improvisations in work equipment;

- making improvised connections of the compressed air supply hoses of the pneumatic equipment;

- work with used work equipment - drilling machines, hammers, mechanically operated cranes, conveyors, metal support, etc.;

- travel, parking in dangerous areas: transport spills, under the load of lifting equipment, on works to evacuate the contaminated air, etc.;

- trips with the danger of falling to the same level by slipping, unbalancing, stumbling, on the road or at work;

- movements with danger of falling from a height, by walking in a vacuum, slipping, unbalancing, on the way to and from work;

b. Omissions:

- non-compliance with work permits, specific work instructions

- omission of operations that ensure safety at work;

- not performing baking or improper baking of the work front;

- omission of the measurement of the concentration of mine gases at the workplace or failure to take measures in case of exceedances of the gas concentration, maximum allowed;

- not carrying out the control of the workplace or not taking remedial measures in case deficiencies are found as a result of the control performed;

- $\quad$ entering the branch under the influence of alcohol or presenting at work in poor health or under the influence of alcohol;

- explosions or ignition of methane due to underground combustion, or the underground introduction of smoking equipment (cigarettes, matches, lighters, etc.) and other objects that may cause a flame or spark (mobile phones, etc.)

- non-use of personal protective equipment and other means of protection (overalls, helmet, boots or boots, protective gloves, self-rescue mask).

The value of the global risk level is calculated with relation 1 based on the "Assessment sheet" 
where:

$$
N_{r}=\frac{\sum_{i}^{64} r R}{\sum_{i}^{64} r}
$$

$\mathrm{N}_{\mathrm{r}}$ is the overall level of risk in the workplace;

$\mathrm{r}_{\mathrm{i}}$ - the rank of the risk factor ,i";

$\mathrm{R}_{\mathrm{i}}$ - the level of risk for the risk factor ,i”;

$\mathrm{u}$ - the number of risk factors identified at work.

The value of the global risk level calculated for the "Miner" job is 3.12 (rel. 1). This value falls into the category of low to medium risk jobs, this value not exceeding the maximum acceptable limit of 3.5.

According to the "Assessment Sheet" made from a number of 64 identified risk factors, only 9 exceed the value of 3 , falling into the category of high risk factors. The rest of the risk factors fall into the category of medium risk factors.

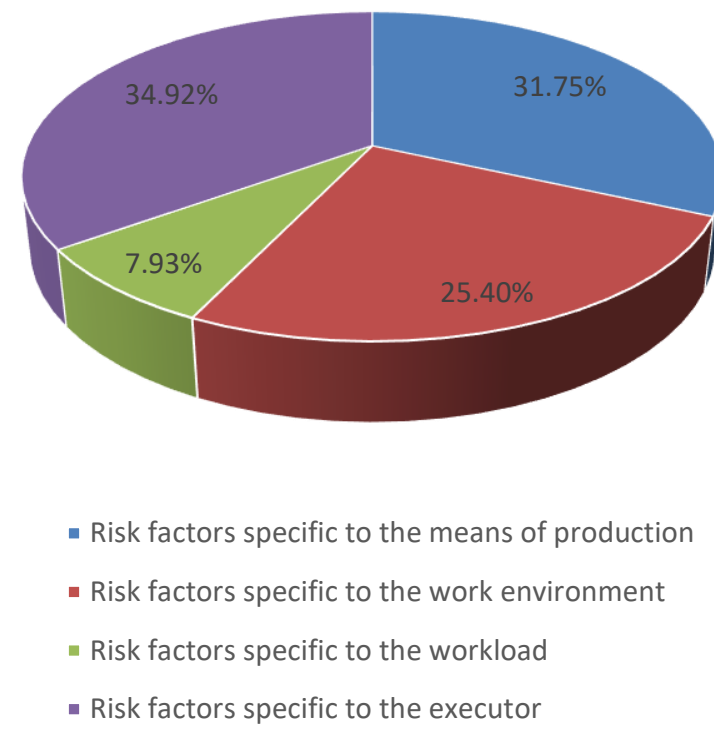

Fig. 1. The share of risk factors identified by the elements of the work system.

Regarding the distribution of risk factors by generating sources, the situation is as follows: (Figure 1)

- $\quad$ risk factors specific to the means of production $31.75 \%$

- $\quad$ risk factors specific to the work environment $25.4 \%$

- $\quad$ risk factors specific to the workload $7.93 \%$

- risk factors specific to the executor $34.92 \%$

\section{Conclusions}

A relatively large number of methods have been designed and are currently used to facilitate the fulfilment of employers' legal obligations in the field of risk assessment.

For risk assessment, we used the method developed by the I.N.C.D.P.M. Bucharest. 
The work was elaborated on the basis of the data provided by the Lupeni Mining Exploitation through the job descriptions, the lists with the technical equipment's, their technical books, the normative for granting the individual protection equipment's, the information about the technological processes, the development of the work process for each job and the plan for the closure and greening of the Lupeni Mining Exploitation received from the management and technical staff of the company, as well as its own observations made during the documentation visits and follow-up of the activity for each job.

The overall risk level calculated for the "Miner" job is equal to 3.12, a value that places it in the category of jobs with a low to medium risk level. This value does not exceed the maximum acceptable limit of 3.5 .

Regarding the distribution of risk factors by generating sources, the situation is as follows:

- $31.75 \%$, factors specific to the means of production / work equipment;

- $\quad 25.4 \%$, factors specific to the work environment;

- $7.93 \%$, factors specific to the workload;

- $34.92 \%$, factors specific to the executor.

\section{References}

1. A Ozunu., C. Anghel, Technological risk assessment and environmental security, Publishing House Accent, Cluj-Napoca, (2007);

2. G. B. Babut, R. I. Moraru, Critical analysis and ways to improve the i.n.c.d.p.m. bucharest risk assessment method for occupational accidents and diseases,

3. G. B. Babut, R. I. Moraru, Occupational Risk Assessment: Imperatives for Process Improvement.Quality - Access to Success, Vol. 19 Issue 166, p133-144. 12p, (2018)

4. G. B. Babut; R. I. Moraru P. S. Mihai; D. N. Fraitag, Understanding and managing worker's exposure to specific risks, MATEC Web of Conferences; Vol. 305, (2020).

5. F. J. G.-Gómez, C. González-Gaya, V. F.. Rosales-Prieto, An Approach to Health and Safety Assessment in Industrial Parks, Sustainability 2020, 12(9) (2020)

6. M. C. Săvulescu, A. C. Tataru, A. Stanci, D. Tataru, Risk factors that may occur in the process of closing and greening the Lupeni Mining Exploitation, International Multidisciplinary Symposium, "Universitaria Simpro 2021" (2021)

7. R.I Moraru,.., G.B Băbuţ., A romanian occupational health and safety risk assessment tool: premises, development and case study. In: Zhang, Z. (Ed.), Risk assessment and management, pp. 292- 311, Academypublish.org (Publishing Services LLC), Cheyenne, WY, USA. (2012) 